\title{
Ethical support to psychiatry residents: a report of a Brazilian ethics consultation group
}

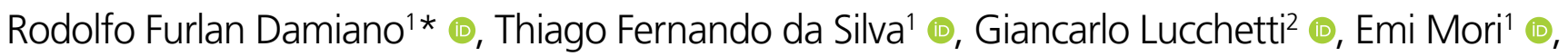 \\ Julia de Melo Koneski $\odot$, Daniel Martins de Barros ${ }^{1} \odot$, Gustavo Bonini Castellana ${ }^{1}$
}

\begin{abstract}
SUMMARY
OBJECTIVE: It is not uncommon for medical residents to deal with critically ill patients who frequently show several ethical and human dilemmas, highlighting the need for a consultation with ethical specialists. The objective of this article is to present a description of a Brazilian Ethics Consultation group designed to attend psychiatry residents.

METHODS: This article reports a case of a critically ill patient with Borderline Personality Disorder with multiple intervention failures and several ethical conflicts who was seen by a resident and supported by an ethics consultation group.

RESULTS: When medical residents and medical staff face severe and unusual ethical dilemmas, they might feel unprepared and have ones' mental health impaired. Thus, this article reports a successful ethics consultation and discusses its development in other academic institutions.

CONCLUSION: Medical educators and staff from academic hospitals should pay attention to the needs of the medical residents. The development and support of ethics consultation groups must be provided to fulfill the need of those residents who face serious ethical and human dilemmas.

KEYWORDS: Psychiatry. Ethics. Ethics consultation. Academic training.
\end{abstract}

\section{INTRODUCTION}

Dealing with critically mentally ill patients involves multiple aspects of subjective dimensions. This complexity raises a series of ethical, legal, and human dilemmas, which includes the patient (and his or her desires, dreams, mental capacity, etc.), the relatives of these patients, the attending physician, and other health professionals. In this context, mental health professionals are constantly exposed to and dealing with multiple ethical issues in their clinical practice ${ }^{1,2}$. Among these professionals, psychiatry residents, who are still under training, need special support when these ethical issues appear, since unsolved conflicts may impact their professionalism and mental health ${ }^{3-5}$.

A study held in fourteen South Korean hospitals and including all residency specialties, showed that $77 \%$ of residents had faced serious ethical dilemmas during their training, and most of them didn't know how to manage them ${ }^{6}$. Surprisingly, most of these residents tried solving their ethical dilemmas by talking to a colleague instead of talking to a supervisor or an ethics specialist. Similar results were found in the US for psychiatry residents, where $76 \%$ of residents reported facing an ethical dilemma that they felt unprepared during their residency training ${ }^{7}$.

\footnotetext{
1 Universidade de São Paulo, Institute of Psychiatry, Clinics Hospital - São Paulo (SP), Brazil.

${ }^{2}$ Universidade Federal do Juiz de Fora, School of Medicine - Juiz de Fora (MG), Brazil.

*Corresponding author: damianorf@gmail.com

Conflicts of interest: the authors declare there are no conflicts of interest. Funding: none.

Received on September 02, 2020. Accepted on September 05, 2020.
} 
These alarming numbers highlight the need for ethical support in residency programs. An important tool to ensure an ethical environment, especially in academic and clinical settings, is the existence of ethics consultation groups. Ethics consultation groups are a team of ethical specialists who can access, evaluate and orientate physicians (either senior or residents) in any kind of ethical conflict that might emerge from a clinical encounter ${ }^{8}$. Resident physicians need education and special support when dealing with ethical conflicts and, the existence of clinical ethics consultation groups could be extremely helpful to them ${ }^{9}$. A previous study ${ }^{10}$ evaluated the knowledge, use, and perceptions of resident physicians from different medical specialties regarding ethics consultation groups. They found that despite that the residents report awareness of ethics consultation services, most of them had never requested one. Thus, it is crucial the need of disseminating ethics consultation groups throughout academic hospitals, particularly for those who deal with medical residents.

This gap is more evident in psychiatry resident programs, where, to our knowledge, there are no studies that report the use or the description of ethics consultation services. As previously described, mental health professionals are vulnerable to several ethical issues and comprehensive support could impact their clinical practice and improve their patient care.

In an attempt to generate further evidence to this topic, the present article aims to discuss the support for psychiatry residents made by an ethics consultation group in Brazil. To illustrate the whole process, a case of a patient diagnosed with severe Borderline Personality Disorder will be used. This patient has been largely refractory for many types of pharmacological and non-pharmacological interventions, and several ethical conflicts have emerged from this complex multi-level approach. The approach includes efforts of a large and diverse clinical staff with different points of view and expectations regarding the patient outcome and the harsh intersection of wills, values, and expectations among physicians and patients, as well as the indent to develop leadership skills in psychiatry residents.

\section{EDUCATIONAL CASE}

This is a 29-year old female, single, childless, and a Jehovah's Witness. Currently unemployed but worked in several (approximately eight) different jobs. She lives with her mother, who herself is treated for depression. Her father divorced her mother when the patient was one year old, abandoning the family. The patient experienced several incidents during childhood and adolescence. Following her father's abandonment, she experienced a difficult relationship with her mother. As religion was very important to her family, she was expected by her family to display a strong religious commitment, which she was unable to do. Due to her smoking and self-injury habits, she was expelled from her religion, which caused her to withdraw from her family. A few years later, the patient initiated self-injurious behavior and mood instability culminating in her first suicide attempt (with rat poison), when she began outpatient care in our psychiatry hospital in specialized outpatient care.

At the start of treatment, the clinical staff reviewed the patient's symptoms and clinical history. The patient presented frantic efforts to avoid abandonment, in addition to demonstrating unstable relationships, impulsivity, suicidal behavior, affective instability, intense anger, delusion-like ideas, and severe dissociative symptoms, having the diagnosis of Borderline Personality Disorder (BPD). In 2018, she was involuntarily hospitalized at our institution, referred by the outpatient physician due to suicidal thoughts, dissociative episodes, and psychotic-like symptoms, for initiation of electroconvulsive therapy (ECT) justified by "multiple inefficacious treatments" and this being "the patient's final chance for treatment", which was immediately refused by the patient.

At admission, the resident physician responsible for her case felt under extreme pressure. The patient did not want ECT, but her psychopathology seems to impair her decision-making capacity ${ }^{11}$. The outpatient physician and her mother strongly supported it, sending several phone messages to the resident physician, sometimes threatening to sue him if he did not accept this indication, even though ECT is not a scientifically validated treatment for BPD patients ${ }^{12,13}$. At that time, the resident felt unable to make the best decision.

In this uncertain scenario, the resident was told that there was a clinical ethics consultant team at the hospital and the team was called to discuss the ethical dilemma and help the decision making. Then, a meeting was held, and the resident was told to present the case to a group of ethics specialists who were not involved with the case. The team urged the resident to discuss the best treatment options for the patient with all members of the clinical staff and the family. The ethics consultation group considered that the patient was, in fact, capable of making decisions regarding the ECT treatment (ability to communicate a choice, in addition to the ability of understanding, appreciation, and reasoning ${ }^{14}$.

Since the ECT was not performed, other treatment options were taken into consideration. Following multiple discussions, the re-introduction of Clozapine was selected as prudent drug therapy for this context (intermediary approach). This drug was the only medication that has been proven to control the patient's impulses and disorganization in the past, despite the risk of neutropenia and low evidence of efficacy ${ }^{15}$, and despite the patient's refusal to be submitted to a weekly blood count, 
which could help identify clozapine-induced neutropenia. The patient and her mother were advised of its risks and agreed with the joint decision (by impatient clinical staff and resident, clinical ethics consultant team, and outpatient clinical staff).

As a result, the resident involved in this case was able and felt prepared to deal with all these medical, legal, and ethical issues, feeling fully supported in this complex and multi-level ethical decision and improving his clinical skills.

\section{ETHICS CONSULTATION GROUP FOR PSYCHIATRIC RESIDENTS}

Figure 1 summarizes the framework of the Ethics Consultation Group of the Institute of Psychiatry of the University of São Paulo, the largest Brazilian university, located in the southwest of Brazil. The consultation group emerged from a forensic psychiatry group of the same institution called NUFOR (Forensic Psychology and Psychiatry Program). The model is based in six steps and will be discussed below, having as an example the case reported above.

First Step (Contact with the ethics consultation group): The first step is the promotion of the ethics consultation group to psychiatry residents. This is not an easy step, since some previous international studies showed that many residents are not aware of the existence of this type of support and also have a negative perception of $\mathrm{it}^{10}$. At our institution, dissemination of the objectives of the group was carried out through leaflets,

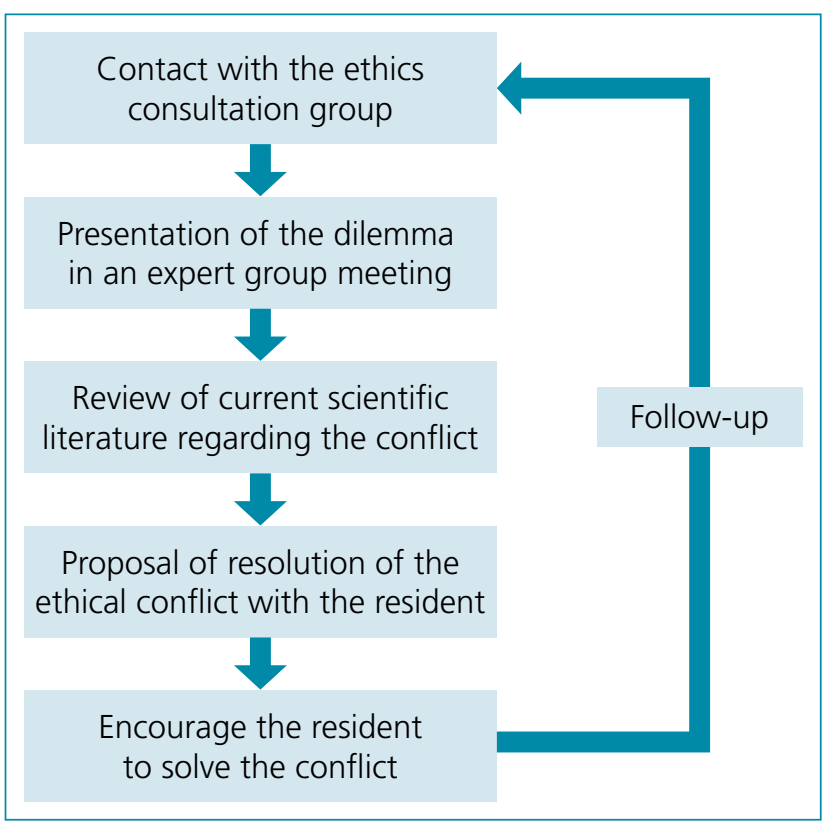

Figure 1. Framework of an ethical consultation group support program to psychiatry residents. banners, meetings, and grand rounds. Then, the first contact is available through the contact with a senior forensic resident, a fourth-year psychiatry resident who usually is a former resident of our institution and has close contact with other peers, or through direct contact with any NUFOR member, where a meeting is set up to present the case to the expert group.

Second Step (Presentation of the dilemma to an expert group meeting): At this time, the resident is responsible to present the case in a meeting open to the scientific community of our institution, organized by NUFOR ethics experts' members. The case is presented and a subsequent discussion about any emerged ethical dilemma is done. NUFOR members use the moral deliberation method proposed by $\mathrm{Gracia}^{16}$ as a theoretical framework. The author proposes that when dealing with an ethical dilemma the health professional should identify different courses of action (extreme, intermediary, and optimal), and always try to choose the more prudential one.

Third Step (Review of the current scientific literature regarding the conflict): The ethical consultants in collaboration with the responsible resident make a large literature review trying to identify similar cases where the specific ethical dilemma was reported. Furthermore, if needed, there is a revision of Brazilian laws to help the entire group in finding the best and the most suitable course of action based on the country's law, avoiding any kind of suing to the medical team.

Fourth Step (Proposal of resolution of the ethical conflict with the resident): Together with the resident and the clinical staff, the ethics consultant group proposes a resolution of the ethical conflict. For example, in the reported case above, there is an urgent need to conciliate all points of view to make the best decision. So, a meeting was proposed among all clinical staff to define a single course of action and thereof having an encounter with the family to explain all discussions and clinical prognosis that all the team (not only the medical resident) decided to the patient as the best course of action.

Fifth Step (Encourage the resident to solve the conflict): This is done throughout all steps. The ethics consultation member supports and encourages the resident to solve the conflict, developing the trainee's academic and personal skills, and if appropriate, present the whole case in a scientific encounter to incentive other mental health professionals to pay deeper attention to how ethical conflicts might emerge and some examples in how solving it appropriately.

Sixth Step (Follow-up): At all times (until the resolution of the conflict) a follow-up is done by the team, and there is an open channel to contact by the resident in any new emerged issue. Moreover, when a new and challenging conflict that deserves another presentation to the group emerges, a new encounter is set up and the steps start again. 


\section{CONCLUSION}

This article discusses the importance of an ethics consultation group for supporting psychiatric residents while dealing with complex ethical and legal dilemmas. In our case scenario, the resident felt unprepared and overwhelmed by many different sources of opinions and information. The support from the ethics group was an important way to overcome these conflicts and helped the resident to further understand the family context, patient's autonomy, and the decision-making process, improving his training, professionalism, and healthcare.

We are aware that there are several pitfalls in implementing it, especially in non-tertiary care services. However, we strongly suggest that resident doctors should be trained to learn how to deal with and conduct this kind of dilemma, in special psychiatry residents, who can be an important tool to support other professionals and specialists dealing with complex ethical conflicts in primary and secondary settings. Furthermore, in the age of technology, online conferences between trained specialists and more junior doctors could be an important alternative to support doctors from distant and less-specialized areas.

\section{AUTHORS' CONTRIBUTIONS}

RFD: Conceptualization, Formal Analysis, Writing - Original Draft, Writing - Review \& Editing. TFS: Conceptualization, Formal Analysis, Writing - Original Draft, Writing - Review \& Editing. GL: Writing - Original Draft, Writing - Review \& Editing. EM: Writing - Review \& Editing. JMK: Writing Review \& Editing. DMB: Conceptualization, Writing - Original Draft, Writing - Review \& Editing. GBC: Conceptualization, Writing - Original Draft, Writing - Review \& Editing.

\section{REFERENCES}

1. Buchanan A. Mental capacity, legal competence and consent to treatment. J R Soc Med. 2004;97(9):415-20. https://doi. org/10.1258/jrsm.97.9.415

2. Buchanan AE, Brock DW. Deciding for Others: The Ethics of Surrogate Decision Making. Cambridge: Cambridge University Press; 1990. https://doi.org/10.1017/CBO9781139171946

3. Brazeau CM, Schroeder R, Rovi S, Boyd L. Relationships between medical student burnout, empathy, and professionalism climate. Acad Med. 2010;85(Suppl 10):S33-6. https://doi. org/10.1097/ACM.0b013e3181ed4c47

4. Keith SJ, Mohl PC. Education of psychiatry residents in ethics. Acad Psychiatry. 1996;20(3):125-6. https://doi.org/10.1007/ BF03341561

5. Hoop JG. Hidden ethical dilemmas in psychiatric residency training: the psychiatry resident as dual agent. Acad Psychiatry. 2004;28(3):183-9. https://doi.org/10.1176/appi.ap.28.3.183

6. Koh Y. Residents' preparation for and ability to manage ethical conflicts in Korean residency programs. Acad Med. 2001;76(3):297-300. https://doi.org/10.1097/00001888200103000-00025

7. Roberts LW, McCarty T, Lyketsos C, Hardee JT, Jacobson J, Walker $\mathrm{R}$, et al. What and how psychiatry residents at ten training programs wish to learn about ethics. Acad Psychiatry. 1996;20(3):131-43. https://doi.org/10.1007/BF03341563

8. La Puma J, Stocking CB, Silverstein MD, DiMartini A, Siegler $M$. An ethics consultation service in a teaching hospital. Utilization and evaluation. JAMA. 1988;260(6):808-11. PMID: 3392812
9. Craig JM, May T. Ethics consultation as a tool for teaching residents. Am J Bioeth. 2006;6(4):25-7. https://doi. org/10.1080/1526516060075549

10. Gacki-Smith J, Gordon EJ. Residents' access to ethics consultations: knowledge, use, and perceptions. Acad Med. 2005;80(2):168-75. https://doi.org/10.1097/00001888200502000-00014

11. Ayre K, Owen GS, Moran P. Mental capacity and borderline personality disorder. BJPsych Bull. 2017;41(1):33-6. https:// doi.org/10.1192/pb.bp.115.052753

12. Kramer BA. Poor response to electroconvulsive therapy in patients with a combined diagnosis of major depression and borderline personality disorder. Lancet. 1982;2(8306):1048. https://doi.org/10.1016/s0140-6736(82)90083-6

13. Lee $J H$, Kung $S$, Rasmussen KG, Palmer BA. Effectiveness of electroconvulsive therapy in patients with major depressive disorder and comorbid borderline personality disorder. J ECT. 2019;35(1):44-7. https://doi.org/10.1097/ YCT.0000000000000533

14. Appelbaum PS. Clinical practice. assessment of patients' competence to consent to treatment. N Engl J Med. 2007;357(18):1834-40. https://doi.org/10.1056/NEJMcp074045

15. Beri A, Boydell J. Clozapine in borderline personality disorder: a review of the evidence. Ann Clin Psychiatry. 2014;26(2):13944. PMID: 24812651

16. Gracia D. Ethical case deliberation and decision making. Med Health Care Philos. 2003;6(3):227-33. https://doi. org/10.1023/a:1025969701538 